\title{
Formação, práticas e trajetórias de aconselhadores de centros de testagem anti-HIV do Rio de Janeiro, Brasil
}

Claudia Mora ${ }^{(a)}$

Simone Monteiro(b)

Carlos Otávio Fiúza Moreira(c)

Mora C, Monteiro S, Moreira COF. Education, practices and paths of counselors at HIV testing centers in Rio de Janeiro, Brazil. Interface (Botucatu). 2015; 19(55):1145-56.

Given the importance of counseling in HIV testing, we analyzed the institutional guidelines, the competencies encouraged during counselors' professional training and these counselors' knowledge and practices. This was a qualitative study based on document analysis, observation and interviews with counselors at HIV testing and counseling centers in the state of Rio de Janeiro. Bourdieu's theory was the foundation for the analysis. It was shown that counselors' professional habitus is produced by the connections between trainings, undergraduate experiences and personal interests and experiences. Putting competencies such as active listening into operation is limited by the routine within the services and lack of opportunities for reflection. In order to improve counseling practices, it is important to develop competencies within training, maintain the inservice education and make adjustments to healthcare service routine. These arrangements may strengthen the transition from guidelines to action and enhance the management and organization of the testing and counseling centers.

Keywords: Counseling. HIV. Sociology. Professional education. Competency-based education.
Perante a importância do aconselhamento na testagem anti-HIV, analisamos as diretrizes institucionais, as competências privilegiadas no treinamento profissional e os saberes/práticas de aconselhadores. Trata-se de estudo qualitativo centrado na análise documental, observação e entrevista com aconselhadores de Centros de Testagem e Aconselhamento (CTA) do estado do Rio de Janeiro. A análise foi orientada pela teoria de Pierre Bourdieu. Foi evidenciado que o habitus profissional dos aconselhadores resulta da articulação dos treinamentos, da graduação e de experiências e interesses pessoais. A operacionalização de competências, como a escuta ativa, é limitada pela rotina dos serviços e escassez de espaços de reflexão. Para incrementar a prática do aconselhamento, é importante desenvolver competências no treinamento, manter a educação continuada e fazer adequações na rotina do serviço. Tais ajustes podem fortalecer a passagem das diretrizes à ação e o aprimoramento da organização e gestão dos CTA.

Palavras-chave: Aconselhamento. HIV. Sociologia. Capacitação profissional. Educação baseada em competências.

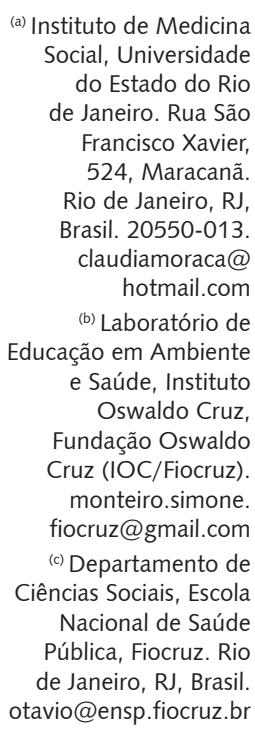




\section{Introdução}

Ao longo das quatro décadas da epidemia de Aids, a oferta de aconselhamento e testagem voluntária tem sido amplamente recomendada no âmbito internacional, por promover adoção de cuidados para: evitar a transmissão do HIV, permitir o início oportuno do tratamento e oferecer acompanhamento aos familiares e parceiros das pessoas que vivem com HIV/Aids (PVHA) e outras doenças sexualmente transmissíveis (DST). Apesar dos limites para avaliar o seu impacto e efetividade, decorrentes das múltiplas formas de oferta da estratégia, sua contribuição é valorizada pelos benefícios na prevenção e garantia de suporte psicossocial no enfrentamento das implicações da testagem ${ }^{1,2}$.

A técnica psicológica do aconselhamento, desenvolvida pela escola humanista, foi incorporada nas recomendações da Organização Mundial de Saúde e dos Centros de Controle e Prevenção de Doenças. Comparado com o referencial da mudança comportamental, tal perspectiva imprimiu um caráter intersubjetivo à prática, estimulando a expressão de sentimentos por parte do usuário e a menor diretividade por parte do profissional ${ }^{3}$.

No Brasil, o aconselhamento em DST/Aids, inicialmente, foi promovido pelas ONGs Aids em meados da década de 1980, haja vista sua capacidade propositiva no plano das estratégias e ações de cuidado e prevenção 4 . A partir de 1988, no contexto da reforma constitucional, da conformação do SUS e da luta da sociedade civil organizada, a oferta de aconselhamento e testagem anti-HIV integrou a resposta à epidemia ${ }^{5}$.

Em meados da década de 1990, em virtude do acesso à terapia antirretroviral (TARV), o sentido do aconselhamento se deslocou do plano assistencial para ações de prevenção e detecção do HIV. Tal enfoque foi impulsionado pela criação dos Centros de Testagem e Aconselhamento (CTA) sob os princípios da confidencialidade, o consentimento informado e o aconselhamento ${ }^{5}$. Atualmente, existem no país 515 unidades distribuídas nas cinco regiões, que contam com aconselhadores, sobretudo, com curso de enfermagem, psicologia e serviço social; ou técnicos e auxiliares de enfermagem, técnicos de laboratório, agentes comunitários de saúde e redutores de danos ${ }^{6}$.

Um dos grandes desafios da operacionalização do aconselhamento em DST/Aids diz respeito ao predomínio do enfoque informativo e à invisibilidade do componente emocional ${ }^{7,8}$. Ademais, as abordagens de aspectos sociais, como os valores e regras culturais, as visões do gênero e da sexualidade e o conhecimento dos direitos civis, são dificilmente apreendidos por manuais ou processos normatizadores ${ }^{8-10}$. Frente ao quadro de heterogeneidade na prática e da necessidade de adensar os saberes técnicos, vários autores sugerem melhorar o embasamento teórico e os processos de formação dos aconselhadores, incluindo as articulações entre teoria e prática ${ }^{11-13}$.

Tendo em vista os investimentos na ampliação da testagem e a manutenção do aconselhamento como estratégia preventiva fundamentada na Abordagem Centrada na Pessoa na última década no país, cabe refletir sobre a formação das equipes dos CTA e suas relações com a prática em si mesma. O presente estudo objetivou contribuir para essa discussão por meio da análise dos processos educacionais específicos para a formação de aconselhadores em DST/Aids, e das trajetórias de um grupo desses trabalhadores que atuam nos CTA do estado do Rio de Janeiro.

O recorte teórico-metodológico da pesquisa foi norteado pela perspectiva praxiológica, na qual a formação para as práticas abrange processos formais de ensino e a experiência profissional, e não apenas uma consagração das posições dominantes dos agentes detentores de um determinado saberfazer. O desdobramento da noção de habitus ${ }^{14}$ acerca da questão profissional reforça o pressuposto de que o trânsito dos agentes por distintos campos do espaço social (lazer, esportes, vida familiar etc.) se reflete nas práticas profissionais ${ }^{15}$.

Como assinalado por Perrenoud ${ }^{16}$, as competências profissionais resultam da apropriação de saberes convencionais (acadêmicos, científicos, técnicos), próprios da profissão. Mais, a conformação de habitus profissionais mobiliza saberes declarativos e procedimentais - não derivados da ciência e da técnica - que garantem a eficácia das ações. Outras leituras construtivistas acerca do desenvolvimento de competências e habilidades profissionais igualmente argumentam que as práticas profissionais se constituem pela via dos processos formais de ensino e de outros processos de socialização ${ }^{17,18}$. 


\section{Metodologia}

Tendo por base o referencial teórico de Bourdieu ${ }^{14}$, considera-se que a gênese da ação deriva dos processos socializadores vivenciados pelos agentes, que se incorporam na forma de disposições ou habitus. Sob esse olhar, a categoria trajetória social é definida pela conformação dos campos e pela formação e expressão dos habitus, a partir de um corpus documental e de narrativas capazes de ilustrar as estratégias, embates, percursos e forças intervenientes na legitimação dos grupos sociais ${ }^{19}$.

Com o propósito de descrever as situações em que os habitus dos agentes são construídos, atualizados e, inclusive, contra-socializado ${ }^{20}$, a pesquisa, de cunho qualitativo, envolveu estratégias metodológicas complementares, quais sejam: análise documental, observação participante e entrevistas semiestruturadas. Identificada como um estudo de caso, centrado na descrição e análise dos contextos e processos relativos a uma intervenção e a um cenário de ação em transformação ${ }^{21}$, a investigação foi desenvolvida em três etapas.

Na primeira, realizou-se a análise dos documentos de referência da prática do aconselhamento em DST/Aids no Brasil, selecionados a partir das referências apontadas nas entrevistas com gestores e aconselhadores e no acervo disponível no site do Departamento de DST/Aids e Hepatites Virais do Ministério da Saúde.

A segunda envolveu a observação participante de três treinamentos (capacitações) em aconselhamento para profissionais que atuavam em unidades do Programa Saúde da Família, policlínicas, CTA, maternidades etc., e do encontro anual de CTA do estado do Rio de Janeiro. Foram também realizadas entrevistas com gestores da Secretaria de Saúde do Estado do Rio de Janeiro, responsáveis pela assessoria técnica e formação sobre aconselhamento em DST/Aids.

$\mathrm{Na}$ terceira etapa, foram feitas entrevistas individuais com vinte aconselhadores de sete CTA do estado do Rio de Janeiro, sobre as características da prática na rotina do serviço, trajetória profissional e visões sobre a Aids e a sexualidade. A maioria dos aconselhadores havia participado de uma capacitação inicial quando ingressaram nos CTA; ademais, uma quarta parte havia participado do treinamento ofertado pela Secretaria Estadual de Saúde. Buscou-se abordar um grupo heterogêneo, caracterizado por 17 mulheres e três homens, com formações e tempos de serviço diversos: enfermagem (seis), psicologia (quatro), técnico de enfermagem (quatro), serviço social (três), fisioterapia (um), farmácia (um) e sociologia (um).

A organização e interpretação do corpus seguiu o método de análise de conteúdo na vertente da análise temática ${ }^{22}$. O material foi lido repetidamente para criar familiaridade com os conteúdos; em seguida, as narrativas das entrevistas foram classificadas por unidades temáticas, para, finalmente, se extraírem as categorias empíricas do estudo e se analisar o corpus.

A pesquisa foi aprovada pelo Comitê de Ética em Pesquisa da Escola Nacional de Saúde Pública e pelo Comitê de Ética em Pesquisa da Secretaria Municipal de Saúde do Rio de Janeiro. O trabalho de campo ocorreu entre outubro de 2011 e dezembro de 2012.

\section{Resultados e discussão}

Para compreender as relações entre as recomendações institucionais, formais ou oficiais, os processos de formação e as práticas de aconselhamento em DST/Aids, será apresentado o conteúdo dos documentos de referência relativo às competências e habilidades esperadas do aconselhador, seguido da descrição das atividades e temas abordados nos processos de capacitação. Por fim, são analisadas as disposições dos aconselhadores para as práticas, decorrentes dos processos de socialização profissional e em outros âmbitos.

\section{Competências dos aconselhadores em DST/Aids nas diretrizes nacionais}

Foi identificado que as atividades dos profissionais dos CTA não se circunscrevem apenas à prática do aconselhamento. As Diretrizes dos $C^{2} A^{5,23}$ incluem atividades internas e interinstitucionais, 
como por exemplo: organização de ações educativas, planejamento do serviço (insumos, identificação da população etc.), articulação com a rede (unidades básicas de saúde, saúde mental, Serviços de Atendimento Especializado - SAE), notificação para vigilância epidemiológica e realização de capacitações para outros serviços.

As competências para o acolhimento, a escuta e a comunicação, contempladas nas diretrizes, dizem respeito ao princípio da integralidade nas ações em saúde e convergem com o espírito inicial dos CTA: oferecer um atendimento não apenas atento aos aspectos biofisiológicos, mas às questões emocionais, familiares, sociais, culturais e políticas dos usuários ${ }^{5}$.

A análise sugere uma convergência entre o desempenho esperado dos profissionais e as competências transversais preconizadas nas Diretrizes Curriculares Nacionais (DCN) para os 14 cursos de nível Superior de graduação

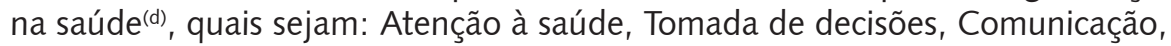
Liderança, Administração e Gerenciamento, e Educação permanente. A tendência atual dos processos de formação profissional no país é desenvolver e avaliar as competências dos egressos com base nesses elementos dos perfis profissionais ${ }^{18}$.

As atividades dos CTA exigem a mobilização de várias dessas competências, como é o caso da comunicação, relevante para o desenho de material informativo e a elaboração de discursos significativos, ao público jovem, sobre sexualidade e saúde sexual, segundo os entrevistados. No entanto, a avaliação do desempenho dos mesmos ainda não se aproxima desse referencial, posto que os mecanismos de avaliação, bem como as orientações para gerar espaços de reflexão acerca das práticas são pouco desenvolvidos ${ }^{8}$.

Quanto às recomendações para o aconselhamento, a 'escuta ativa' dos sentimentos, atitudes e valores dos sujeitos relativos ao diagnóstico de DST e HIV constitui o norte de três documentos complementares: Manual de treinamento em aconselhamento em DST, HIV e Aids ${ }^{24}$, Aconselhamento em DST, HIV e Aids: diretrizes e procedimentos básicos ${ }^{25}$ e Diretrizes dos CTA ${ }^{5,23}$. Esses desempenhos envolvem, segundo a demanda do usuário, o uso de saberes convencionais, especialmente sobre as DST e suas formas de prevenção, e procedimentais, como a comunicação e a empatia. Entretanto, a incorporação da Abordagem Centrada na Pessoa e da escuta ativa nos serviços de saúde apresenta entraves devido à força das rotinas institucionais, somados à escassez de ferramentas técnicas e de disposições dos profissionais para acolher as demandas relativas à saúde sexual. Essas falências são ilustradas por pesquisas com foco no público masculino homossexual| ${ }^{26}$, e nos cenários de oferta da testagem na atenção básica ${ }^{27}$ e nas maternidades ${ }^{28}$.

Nos CTA, a incorporação de um formulário de avaliação de riscos na prática do aconselhamento traz alguns empecilhos para 'acolher a subjetividade dos usuários', como reforçado no Manual simplificado em aconselhamento em DST/ HIV/Aids para a Atenção Básica ${ }^{29}$. Souza et al. ${ }^{30}$ assinalam que as questões do instrumento, em muitos casos, não condizem com o contexto dos usuários, além de considerá-lo invasivo. Monteiro et al. ${ }^{31}$, por sua vez, notam o pouco espaço que resta para abordar aspectos caros a uma visão compreensiva da prevenção das DST/Aids, como os significados e a diversidade das experiências sexuais dos sujeitos. Adicionalmente, Pupo e Ayres ${ }^{13}$ notam a concorrência de duas racionalidades na prática analisada: os aconselhadores precisam contemplar a demanda dos usuários e as metas em saúde pública acerca das DST/Aids. Segundo os autores, faz-se necessário garantir que o aconselhamento aborde os aspectos afetivo-emocionais e socioculturais do contexto dos usuários para auxiliá-los na resolução de seus objetivos singulares.

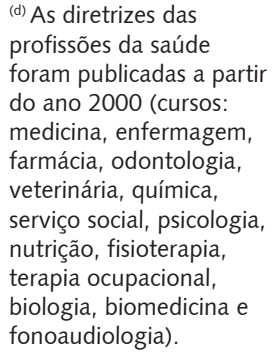

(d) As diretrizes das profissões da saúde foram publicadas a partir do ano 2000 (cursos: medicina, enfermagem, farmácia, odontologia, veterinária, química, serviço social, psicologia, nutrição, fisioterapia, terapia ocupacional, biologia, biomedicina e fonoaudiologia). 
Em 2010, o Ministério da Saúde ${ }^{32}$ divulgou um documento que atualiza as diretrizes para o aconselhamento, redefinido como:

Uma abordagem onde o usuário é estimulado a expressar o que sabe, pensa e sente acerca das DST/Aids e o profissional de saúde, ao escutá-lo pode contribuir para a avaliação de suas vulnerabilidades e para a identificação de medidas preventivas, segundo as possibilidades e limites de cada pessoa em atendimento. (p. 8 )

Este conceito amplia as perspectivas de instrumentalização da abordagem da vulnerabilidade no aconselhamento ao fortalecer duas ações interdependentes: a análise dos aspectos individuais, sociais e programáticos que constrangem a situação dos usuários, e o desenvolvimento do diálogo sob uma abordagem construtivista, que favoreça sua capacidade de resposta enquanto sujeitos de direitos. Entretanto, como se retratará a seguir, existem desafios programáticos relativos aos processos de formação com ênfase nessa abordagem.

\section{Formação para o aconselhamento em DST/Aids: temas e práticas}

Segundo depoimento dos gestores da Gerência Estadual de DST/Aids do Rio de Janeiro, desde o início dos anos 2000 a equipe da área de prevenção organiza os treinamentos para os novos aconselhadores em DST/Aids do estado. Ademais, em razão das condições estruturais a serem equacionadas para alcançar as metas institucionais, como a redução no tempo dos treinamentos (antigamente de quarenta horas) e do desequilíbrio entre o tamanho da referida equipe (três integrantes) e a quantidade de municípios do estado (92), tem-se estimulado a assessoria de grupos de referência regionais para os treinamentos.

Quanto ao contexto programático mais amplo no qual se inserem os CTA, cabe lembrar que o processo de descentralização e municipalização das ações de prevenção e assistência à Aids, ocorrido na última década, trouxe consequências no nível local, como, por exemplo: a redução dos recursos humanos nas equipes técnicas, a menor atenção aos grupos mais vulneráveis e o enfraquecimento do apoio das $\mathrm{ONGs}^{33}$.

No encontro anual dos CTA em 2011, os atores das esferas municipal e estadual expressaram que, por conta da multiplicidade na organização dos serviços de saúde e da rotatividade dos recursos humanos, a formação dos aconselhadores comportava, pelo menos, duas opções: 1) Treinamentos teórico-práticos, que dependem da demanda dos programas municipais de DST/Aids; 2) Treinamentos baseados na observação de pares e supervisão, que são organizados pelos próprios serviços. Devido às variações no tempo de atuação nos CTA, entre um e vinte anos, os aconselhadores passaram por, pelo menos, uma das modalidades de socialização para a prática. Já os mais antigos relataram ter participado nos processos de formação anteriores à disponibilização da TARV, além da estruturação dos programas e serviços de prevenção das DST/Aids dos municípios estudados.

As três capacitações observadas integravam a estratégia de implementação dos testes rápidos para diagnóstico do HIV e para triagem de sífilis e Hepatites B e C, nos quais dois dias eram dedicados às tecnologias diagnósticas e um ao aconselhamento. Esses treinamentos ocupavam um espaço importante na agenda institucional, trazendo novos desafios aos profissionais de distintos serviços, dos quais se espera o uso adequado dos testes e, ao mesmo tempo, a adoção de uma postura dialógica junto ao usuário, como preconizado nas recomendações nacionais.

O treinamento, organizado pela Gerência Estadual, tem por base documentos de referência para o aconselhamento no país e visa reconstruir os conhecimentos e habilidades relativos à prática e explorar as construções subjetivas acerca das DST/Aids a partir de cinco eixos: 1) Informações sobre DST/Aids; 2) Questões éticas (mitos e tabus sobre sexualidade); 3) Interação, estabelecimento de relações de confiança e escuta; 4) Discussão de casos; 5) Síntese do conceito de aconselhamento.

No início, os participantes, em boa parte mulheres e com formação em enfermagem, eram convidados a explicitar suas expectativas em relação ao treinamento. Algumas se relacionavam com a interação com os usuários, como por exemplo: aprender a comunicar o resultado positivo, no sentido 
de saber "como falar, abraçar, encaminhar e lidar com sentimentos de angústia". Outros participantes destacaram "o cuidado e a escuta". Aspectos técnicos da testagem rápida, especialmente a leitura do resultado, também geravam inquietações.

As expectativas perante a entrega dos resultados podem estar relacionadas não apenas à mobilização de representações ligadas à Aids, mas ao vácuo na formação dos habitus profissionais para abordar os aspectos psicossociais na atenção em saúde. Uma pesquisa etnográfica acerca da formação médica ${ }^{34}$ ajuda a compreender como o cultivo do habitus profissional é atravessado pela tensão estruturante entre o saber e o sentir, que implica a separação entre os aspectos científico-racionais e os afetivo-sociais. Essa matriz pode prevalecer nas distintas áreas de atuação no campo da saúde, imprimindo, nos processos de formação profissional, uma omissão ou minimização das oportunidades para se compreenderem os aspectos psicossociais que perpassam a relação com os usuários, como sinalizado por Paiva ${ }^{35}$. A despeito de as reformas curriculares pós-DCN no Brasil proporem transformações no ensino nos cursos da área da saúde, as mudanças nas práticas de ensino são um processo gradual, com resultados a médio e longo prazo ${ }^{36}$.

No que tange aos componentes do aconselhamento recriados nos treinamentos, as observações das atividades evidenciam o modo como competências e atitudes são reforçadas ou atualizadas na interação entre pares. Em uma atividade de discussão de situações de aconselhamento para o HIV e outras DST, enquanto alguns participantes encenavam o caso analisado, os facilitadores introduziam pausas para discutir os conteúdos e atitudes abordados ou ignorados pelos atores.

As reflexões dos participantes revelam compreensões distintas acerca da condução da situação. Por exemplo, o profissional que interpreta o papel do usuário percebe que a aparente abordagem 'diretiva e julgadora' dificulta o acolhimento, enquanto os observadores atentam para o não-retorno do usuário decorrente dessa abordagem e para a postura corporal na comunicação do resultado.

Como contraponto, em outra atividade sobre as ações essenciais do aconselhamento, a capacidade de explorar as chances de exposição às DST/Aids era acionada invariavelmente pelos participantes. Ou seja, o componente da avaliação de risco com base nas práticas sexuais, no uso do preservativo etc., parecia ter sido incorporado previamente e de modo homogêneo.

As observações das atividades corroboram o pressuposto de que, nas competências para as práticas sociais, as experiências significativas tendem a ser mais duráveis ao se inscreverem na memória do corpo dos agentes, quando comparado à força das experiências ou discursos posteriores menos incorporados à estrutura do habitus ${ }^{37}$. Ainda nessa direção, Moreno ${ }^{38}$ aponta a influência da formação profissional na abordagem do aconselhador, podendo ser ora prescritiva ora construtiva, destacando a importância das capacitações periódicas com foco na escuta do usuário e nas demandas dos profissionais.

Tendo em vista os limites de tempo para discutir, em profundidade, todos os assuntos levantados nas atividades, os organizadores destacam o princípio da integralidade como meio e a produção de saúde como fim das práticas de aconselhamento e testagem em DST/Aids. Igualmente, é relativizado o fato de não haver uma forma padronizada para se realizarem as práticas, na medida em que estas emergem de uma sutil combinação de contexto, 'estruturas estruturadas' (habitus) e ação.

Após esse treinamento inicial, os espaços para refletirem e renovarem os conceitos e as práticas costumam ocorrer: nos encontros dos CTA do estado, nas reuniões de equipe e, por vezes, na participação em eventos, especialmente sobre Aids, prevenção e educação. Contudo, os entrevistados revelaram que as oportunidades para participar nestes últimos vêm diminuindo nos últimos anos.

\section{Reconstrução das posições no campo da saúde e disposições para as práticas no universo pesquisado}

Os relatos acerca da redução do espaço físico dos CTA, particularmente aqueles inseridos em unidades de saúde que albergam distintos setores, apontam para as tensões que os agentes vivenciam devido às singularidades do serviço, especialmente pelas imprecisões na quantificação de seus resultados. 


\footnotetext{
(e) Daqui em diante as narrativas citadas levam nomes fictícios e, a fim de ilustrar a diversidade do grupo pesquisado, é informada a formação profissional.
}

As narrativas evidenciaram a persistência da visão hierárquica entre categorias profissionais, que gera uma distinção entre práticas tidas ora como essenciais ora periféricas; integrantes de um mesmo CTA ilustram tal percepção(e):

"A prevenção às vezes fica um pouquinho de lado, eles (os gestores) dão mais assistência à assistência". (Creuza, assistente social)

“O CTA tem uma função muito importante na saúde, na prevenção e na atenção. É o CTA que indica, que consegue chegar até o usuário e falar claramente, agora tem que ter a continuidade no SAE ou nas outras unidades, porque as pessoas que fazem o teste aqui vão voltar para suas unidades, mas eu não vejo isso. Eu trabalhei num hospital e é muito difícil, os médicos não falam e quando têm um resultado você vê que eles procuram: 'vá falar com a assistente social para ver aonde é que você vai'. Às vezes não dão nem o resultado, às vezes não querem solicitar o teste". (Cristina, assistente social)

A subestimação das ações de cunho psicossocial tem relação com a persistência das representações ancoradas no paradigma biomédico, que atribui um valor diferenciado ao diagnóstico e aos conhecimentos especializados ${ }^{34}$. Além disso, as transformações na produção do cuidado em saúde, na qual a produtividade e o uso de tecnologias duras têm um lugar privilegiado ${ }^{39}$, podem contribuir para a percepção dos informantes da ausência de reconhecimento dos CTA e do aconselhamento, caracterizado como uma tecnologia leve ou relacional.

Por outra parte, as manifestações de reconhecimento por parte dos usuários devido às informações ou esclarecimentos fornecidos foram expressivas. $\mathrm{O}$ retorno dos usuários pelo 'respeito' e 'bom trato' suscita comparações positivas entre o CTA e outros serviços, tanto da rede pública quanto particular, como vocalizado por Carmen (farmacêutica), para quem um usuário comentou: "Isso aqui nem parece que é SUS, você parece estar num outro mundo", ao qual ela respondeu: "É o SUS todo é que tem que ser assim!".

O interesse do grupo em ampliar seu capital simbólico motivou mais da metade a realizar cursos de especialização ou uma segunda formação profissional, para além dos treinamentos já descritos. Segundo relatado, no contexto desses cursos, os aconselhadores analisaram assuntos como: a feminização da Aids, a assistência aos casais sorodiscordantes, a Aids e a cidadania, entre outros.

As narrativas do grupo acerca das motivações para continuar no CTA apontam para a satisfação pelo papel desempenhado, em razão de promover a diminuição de novas infecções e atestar a recuperação da saúde dos usuários soropositivos. O mais próximo de um indicador de sucesso do aconselhamento para os profissionais é o retorno dos usuários para buscarem preservativos ou a adesão à TARV, verificável quando há comunicação direta entre o CTA e os serviços de referência. Uma revisão da literatura sobre a estratégia de testagem e aconselhamento destaca a necessidade da ampliação dos critérios de avaliação da estratégia para além das mudanças comportamentais, isto é, para seus benefícios individuais e coletivos em médio e longo prazo ${ }^{40}$.

Seguindo as hipóteses relativas à formação do habitus profissional na perspectiva praxiológica, cabe ilustrar a visão dos agentes acerca do desenvolvimento, nas suas trajetórias, de disposições para o aconselhamento. Os elementos considerados mais significativos na construção e atualização do habitus variam segundo a formação profissional de base, mas, também, dos 
aprendizados decorrentes de estágios e dos interesses cultivados ao longo da experiência profissional. Esses interesses colaboram para a ampliação da perspectiva da prevenção para além da dimensão biológica, como no caso de Antônio (enfermeiro), para quem o desempenho na área da saúde mental o tornou sensível à escuta, o que contribui para a referência dos usuários com demandas relativas aos serviços psicológicos.

Em relação à mobilização de saberes para a realização do aconselhamento, é relevante lembrar que a maioria dos entrevistados relatou que, a partir do seu ingresso no CTA, procurou se informar mais sobre as DST/Aids. A exploração desses saberes passou pelas implicações clínicas e sociais da Aids na trajetória de Rosa (técnica de enfermagem e assistente social). No fim da década de 1990, em um contexto de resistência dos profissionais frente à assistência de PVHA, ela integrou-se às ações impulsionadas por um médico da mesma unidade na qual atuava. Além das discussões de material científico sobre o tema, os aprendizados de Rosa resultaram das atividades desenvolvidas junto às famílias e amigos dos soropositivos, somados às ferramentas adquiridas em um curso de especialização na área social.

Em relação à transferência de disposições originadas no âmbito pessoal, foram feitas poucas inferências, em parte porque as narrativas integravam ambas as dimensões, a pessoal e a profissional. Duas psicólogas ilustram essa tendência. Ana atribui à atitude de se "colocar no lugar dos outros" às relações familiares e às suas reflexões sobre o impacto do preconceito no cuidado da saúde, a partir de experiências pessoais de adoecimento e dos relatos dos usuários com práticas homossexuais. Segundo Maria, a abordagem da sexualidade está presente no seu agir na casa e no trabalho:

"A área de Aids envolve a parte mais importante para a população: sexo. Tem gente que me acha muito escrachada, porque eu falo de sexo, não sei se por conta daqui (CTA) ou da psicologia, ou por conta de mim mesma, eu falo de sexo aberto. Meu filho quando começou a ficar adolescente, deixei camisinha na gavetinha dele. Mãe: que é isso? Para a hora que você precisar".

No que tange à relevância dos processos de capacitação para o aconselhamento, os relatos apontaram para uma dinâmica bidirecional entre a experiência decorrente das situações vividas no serviço e as ferramentas apreendidas nos espaços de formação. A participação nos treinamentos teórico-práticos e a observação de pares parecem contribuir de modo consistente para a incorporação dos aspectos estruturais da prática. Andrea, formada em enfermagem e com experiência na atenção básica, participou da organização de um CTA tendo como referente o acompanhamento das atividades de um serviço homólogo. Após a inauguração do serviço, participou de um treinamento formal para o aconselhamento, o que representou um estímulo para integrar os saberes de referência acerca da organização do CTA e do aconselhamento (recomendações, manuais, apostilhas, etc.), e o saber-fazer decorrente das práticas cotidianas. Entretanto, Rita (técnica de enfermagem e assistente social) revela os limites das capacitações em relação à passagem para a prática; apesar de sua relevância técnica, ela aponta que sua disposição pessoal foi relevante:

"Saber se eu ia conseguir lidar com essas pessoas eu não sabia, mas eu acho que por ter feito serviço social eu me interessei, fiz o curso e vamos tentar! Comecei a fazer o aconselhamento, não vou dizer para você que foi fácil. Você entregar um resultado positivo. Apesar de ter feito aquele treinamento eu precisei reunir todas as minhas forças. Ter alguma reflexão sobre aquilo para estar fazendo".

Ainda nesta direção, foi observado que representações e atitudes para as práticas podem ser reconstruídas a partir da experiência do aconselhamento no CTA. As narrativas indicam como as implicações sociais da Aids, percebidas no atendimento, transformam positivamente as visões dos profissionais sobre assuntos como o preconceito e a diversidade sexual; ademais, colaboram na compreensão dos entraves e benefícios da rede de assistência às PVHA. 
Com base nas narrativas do grupo, considera-se que os treinamentos baseados na observação de pares estimulam a mobilização de saberes e habilidades para desenvolver uma abordagem própria e constatar a diversidade de demandas do público. Cabe salientar a complementaridade de ambos os modos de treinamento e seus limites em termos de aprofundamento acerca da dimensão social da Aids e sua abordagem nas práticas, como: o preconceito e o estigma ${ }^{26,41}$, as experiências sexuais ${ }^{31}$, e a dimensão subjetiva do aconselhamento ${ }^{10,38}$.

\section{Considerações finais}

Por meio da análise das diretrizes institucionais, da observação dos processos de formação (treinamento) e da operacionalização do construto habitus profissional, foi possível identificar os modos como as disposições dos aconselhadores, decorrentes dos processos de socialização, convergem em maior ou menor grau com competências fundamentais ao aconselhamento, como a escuta ativa.

Tal enfoque objetiva demonstrar que a incorporação da abordagem das competências pode contribuir nos processos de formação, monitoramento e avaliação expressos nos documentos de referência. Na perspectiva da Noção Integrada de Competência, a flexibilidade na execução de uma prática profissional não inviabiliza uma avaliação objetiva da mesma ${ }^{17}$. Desse modo, vislumbra-se que a prática do aconselhamento em DST/Aids, alicerçada por um conjunto de habilidades de distinta ordem (cognitivas, atitudinais, comunicativas), pode ser qualificada, ainda, reconhecendo as variações entre categorias profissionais e interpessoais.

A análise realizada dos processos estruturantes da prática evidencia uma articulação entre o saber e o saber-fazer na fase inicial dos profissionais nos serviços de prevenção. Neste sentido, a atualização das práticas a partir da Educação Permanente em Saúde, que dimensiona os processos de trabalho como espaços de aprendizagem e de produção de conhecimento na prática e pela prática, parece necessária e oportuna ${ }^{42}$. Este desafio, válido para o campo da saúde em sentido amplo, é justificado pela complexidade das práticas de aconselhamento, em termos da passagem dos princípios à ação, pela dimensão subjetiva em jogo nas interações profissional-usuário e pelo potencial de aprimoramento da organização e gestão dos serviços.

Dado que as práticas cotidianas são atravessadas por situações que fogem do escopo e finalidade dos manuais e processos de capacitação para o aconselhamento, o desafio de sintonizar os processos de formação e os processos de trabalho pode ser assumido por meio de processos de educação permanente com foco nos profissionais e nos contextos institucionais nos quais a prática acontece. Quanto aos aconselhadores em DST/Aids, que atuam nos distintos serviços do SUS, cabe aprimorar as competências esperadas dos mesmos e a operacionalização dos princípios da confidencialidade, o aconselhamento e o consentimento informado. Em relação aos aconselhadores dos CTA, é necessário revisar a organização das atividades de prevenção em função da integralidade das ações, e analisar sua contribuição no cuidado das PVHA por meio da estratégia de apoio matricial e equipe de referência, como discutido por Haag et al. ${ }^{43}$.

À semelhança dos processos de construção das diretrizes produzidas nos últimos vinte anos no Brasil - que resultaram da concatenação de conceitos e aprendizados resultantes da expansão da prática ${ }^{3,8}$-, é preciso realimentar as bases dos processos de formação, com ênfase nas práticas sociais que determinam os rumos da epidemia. Gerar esses processos de atualização se relaciona com o desafio de operacionalizar o conceito de vulnerabilidade nas estratégias e ações de cunho psicossocial ${ }^{35}$. Para tanto, é primordial motivar o diálogo em torno da noção de aconselhamento, preconizada nas diretrizes, articulado ao conhecimento local (atestado pela produção de documentos acadêmicos por parte dos aconselhadores que analisam aspectos relativos aos serviços), à experiência de atuação interdisciplinar das equipes e ao olhar dos usuários.

Por fim, cabe sinalizar que a materialização das diretrizes para o aconselhamento e a virtual reformulação do papel do CTA na rede de assistência às DST/Aids tem, como pano de fundo, o contexto programático da descentralização da testagem e da ampliação do acesso à TARV, além dos 
desafios na gestão local dos programas de DST/Aids ${ }^{33}$. Considerando que a sinergia e continuidade das ações de prevenção são fundamentais para gerar transformações duradouras nas práticas de cuidado à saúde sexual ${ }^{1}$, é relevante frisar que investimentos na ampliação das estratégias de prevenção, em especial aquelas de alcance social, decerto potencializará os benefícios individuais e coletivos do aconselhamento.

\section{Agradecimentos}

À Gerência de DST/Aids e Hepatites Virais da Secretaria Estadual de Saúde do Rio de Janeiro, e às equipes dos Centros de testagem e Aconselhamento pesquisados, sob gestão de cinco Programas Municipais de DST/Aids. Ao Programa PEC-PG (CAPES/CNPq), pela bolsa de doutorado concedida à primeira autora (2010-2014), cuja tese derivou no presente artigo.

\section{Colaboradores}

Claudia Mora responsabilizou-se pela pesquisa, coleta e análise dos dados, e pela redação do artigo; Simone Monteiro e Carlos Otávio Fiúza Moreira orientaram o planejamento e execução da pesquisa e participaram da redação e revisão final do artigo.

\section{Referências}

1. Tarantola D. HIV testing: breaking the deadly cycle. Health Hum Rights. 2005; 8(2):3741.

2. Kippax S. A public health dilemma: a testing question. AIDS Care. 2006; 18(3):230-5.

3. Fernandes N. Vulnerabilidade ao HIV/aids entre casais sorodiscordantes acompanhados no Instituto de Pesquisa Clínica Evandro Chagas/Fiocruz [tese]. Rio de Janeiro (RJ): Fundação Oswaldo Cruz; 2013.

4. Ramos S. O papel das ONGs na construção de políticas de saúde: a aids, a saúde da mulher e a saúde mental. Cienc Saude Colet. 2004; 9(4):1067-78.

5. Ministério da Saúde. Diretrizes dos Centros de Testagem e Aconselhamento - CTA. Brasília (DF): MS; 1999.

6. Ministério da Saúde. Centros de Testagem e Aconselhamento do Brasil. Desafios para a equidade e o acesso. Brasília (DF): MS; 2008. (Série Estudos Pesquisas e Avaliação, n¹1).

7. Filgueiras S, Deslandes S. Avaliação das ações de aconselhamento. Análise de uma perspectiva de prevenção centrada na pessoa. Cad Saude Publica. 1999; 15 Supl 2:S121-31.

8. Araújo CLF, Camargo Júnior KR. Aconselhamento em DST/HIV: repensando conceitos e práticas. Rio de Janeiro: Folha Carioca; 2004.

9. Ferreira MPS, Silva CMF, Gomes MCF, Silva SMB. Testagem sorológica para o HIV e a importância dos Centros de Testagem e Aconselhamento resultados de uma pesquisa no município do Rio de Janeiro. Cienc Saude Colet. 2001; 6(2):481-90.

10. Galindo WCM, Francisco AL, Rios LF. Proposições para a formação de aconselhadores em HIV/Aids. Physis. 2013; 23(3):741-61. 
11. Dolcini MM, Canin L, Gandelman A, Skolnik H. Theoretical domains: a heuristic for teaching behavioral theory in HIV/STD prevention courses. Health Promot Pract. 2004; 5(4):404-17.

12. Paiva $V$, Pupo LR, Barboza R. The right to prevention and the challenges of reducing vulnerability to HIV in Brazil. Rev Saude Publica. 2006; 40 Supl:109-19.

13. Pupo LR, Ayres JRCM. Contribuições e limites do uso da Abordagem Centrada na Pessoa para a fundamentação teórica do aconselhamento em DST/Aids. Temas Psicol. 2013; 21(3):1089-106.

14. Bourdieu P. Razões práticas: sobre a teoria da ação. Campinas: Papirus; 1996.

15. Lahire B. Homem plural: os determinantes da ação. Petrópolis: Vozes; 2002.

16. Perrenoud P. Práticas pedagógicas, profissão docente e formação: perspectivas sociológicas. Lisboa: Publicações Dom Quixote; 1993.

17. Hager P, Gonczi A. What is competence? Med Teach. 1996; 18(1):15-8.

18. Lima V. Competência: distintas abordagens e implicações na formação de profissionais de saúde. Interface (Botucatu). 2005; 9(17):369-79.

19. Montagner MA. Trajetórias e biografias: notas para uma análise bourdieusiana. Sociologias. 2007; 9(17):240-64.

20. Lahire B. Patrimônios individuais de disposições. Para uma sociologia à escala individual. Soc Prob Prat. 2005; (49):11-42.

21. Minayo MCS. La artesanía de la investigación cualitativa. Buenos Aires: Editorial Lugar; 2009.

22. Bardin L. Análise de conteúdo. Lisboa: Edições 70; 1977.

23. Ministério da Saúde. Diretrizes dos Centros de Testagem e Aconselhamento - CTA. Brasília (DF): MS; 2010.

24. Ministério da Saúde. Coordenação Nacional de DST e Aids. Manual de treinamento em aconselhamento em DST, HIV e Aids. Brasília (DF): MS; 1998.

25. Ministério da Saúde. Aconselhamento em DST, HIV e Aids: diretrizes e procedimentos básicos. 2a ed. Brasília (DF): MS; 1998.

26. Araújo MAL, Montagner MA, Silva RM, Lopes FL, Freitas MM. Symbolic violence experienced by men who have sex with men in the Primary Health Service in Fortaleza, Ceará, Brazil: negotiating identity under stigma. AIDS Patient Care STDs. 2009; 23(8):663-668.

27. Silva SMB. O diagnóstico anti-HIV no município do Rio de Janeiro: processos de cuidado em saúde [tese]. Rio de Janeiro (RJ): Universidade do Estado do Rio de Janeiro; 2011.

28. Fonseca $P$ L, Iriart JAB. Aconselhamento em DST/Aids às gestantes que realizaram o teste anti-HIV na admissão para o parto: os sentidos de uma prática. Interface (Botucatu). 2012; 16(41):395-407.

29. Ministério da Saúde. Manual simplificado em aconselhamento em DST/HIV/Aids para a Atenção Básica. Brasília (DF): MS; 2003.

30. Souza V, Czeresnia D, Natividade C. Aconselhamento na prevenção do HIV: olhar dos usuários de um centro de testagem. Cad Saude Publica. 2008; 24(7):1536-44.

31. Monteiro S, Brandão E, Vargas E, Mora C, Soares P, Daltro E. Discursos sobre sexualidade em um Centro de Testagem e Aconselhamento (CTA): diálogos possíveis entre profissionais e usuários. Cienc Saude Colet. 2014; 19(1):137-46.

32. Ministério da Saúde. Diretrizes para o aconselhamento em DST/Aids [Internet]. 2010 [acesso 2013 Nov 1]. Disponível em: http://www.aids.gov.br/sites/default/files/anexos/ page/2012/52294/teorizacao_oficina_acs.pdf 
33. Grangeiro A, Escuder MM, Gianna MC, Castilho EAC, Teixeira PR. Estratégias de descentralização e municipalização da resposta à aids no Brasil: implicações para as secretarias de saúde e organizações não governamentais. Tempus Acta Saude Colet. 2010; 4(2):14-33

34. Bonet O. Saber e sentir: uma etnografia da aprendizagem da biomedicina. Rio de Janeiro: Editora Fiocruz; 2004.

35. Paiva V. A dimensão psicossocial do cuidado. In: Paiva V, Calazans G, Segurado A, organizadores. Vulnerabilidade e Direitos Humanos: prevenção e promoção da saúde. São Paulo: Juruá; 2013. Livro 2, p. 41-72.

36. Perrenoud P. A prática reflexiva no ofício do professor: profissionalização e razão pedagógica. Porto Alegre: Artmed; 2002.

37. Bourdieu P. A economia das trocas linguísticas. In: Ortiz R, organizador. Bourdieu Sociologia. São Paulo: Ática; 1983. p. 156-83. (Coleção Grandes Cientistas Sociais, nº 39).

38. Moreno DMFC. Aconselhamento para revelação do diagnóstico de infecção pelo HIV. In: Paiva V, Calazans G, Segurado A, organizadores. Vulnerabilidade e Direitos Humanos: prevenção e promoção da saúde. São Paulo: Juruá; 2013. Livro 2, p. 165-88.

39. Merhy EE. Um ensaio sobre o médico e suas valises tecnológicas. Contribuições para compreender as reestruturações produtivas do setor Saúde. Interface (Botucatu). 2000; 4(6):109-16.

40. Mora C, Monteiro S, Moreira CO. Ampliación de las estrategias de consejería y prueba del VIH: desafíos técnicos y tensiones ético-políticas. Salud Colect. 2014; 10(2):253-64.

41. Parker R. Stigma, prejudice and discrimination in global public health. Cad Saude Publica. 2012; 24(7):1536-44.

42. Ceccim RB. Educação Permanente em Saúde: desafio ambicioso e necessário. Interface (Botucatu). 2005; 9(16):161-8.

43. Haag CB, Gonçalves TR, Barcellos NT. Gestão e processos de trabalho nos Centros de Testagem e Aconselhamento de Porto Alegre-RS na perspectiva de seus aconselhadores. Physis. 2013; 23(3):723-39.

Mora C, Monteiro S, Moreira COF. Formación, prácticas y trayectorias de consejeros de centros de test anti-VIH de Río de Janeiro, Brasil. Interface (Botucatu). 2015; 19(55):1145-56.

Considerando la importancia de la consejería para la prueba de $\mathrm{VIH}$, analizamos las directrices institucionales, las competencias privilegiadas en la capacitación profesional y los saberes/prácticas de consejeros. Se trata de un estudio cualitativo concentrado en el análisis documental, observación y entrevista con consejeros de Centros de Testeo y Consejería (CTA, por sus siglas en portugués) del Estado de Río de Janeiro. La orientación del análisis fue la teoría de Pierre Bourdieu. Se puso en evidencia que el habitus profissional de los consejeros es resultado de la articulación de las capacitaciones, del curso de pregrado y de las experiencias e intereses personales. La puesta en operación de competencias, tales como la escucha activa, está limitada por la rutina de los servicios y la escasez de espacios de reflexión. Para aumentar la práctica de la consejería cabe desarrollar competencias en la capacitación, mantener la educación continuada y hacer adecuaciones en la rutina del servicio. Tales ajustes pueden fortalecer el paso de las directrices hacia la acción y el perfeccionamiento de la organización y gestión de los CTA.

Palabras clave: Consejería. VIH. Sociología. Capacitación profesional. Educación basada en competencias.

Recebido em 11/08/14. Aprovado em 02/01/15. 